\title{
Effects of Moderate Amounts of Sulfur Substitutional Impurities on ZnO Using Density Functional Theory
}

\author{
Manuel Alberto Flores-Hidalgo ${ }^{\dagger}$, Diana Barraza-Jiménez ${ }^{\dagger \dagger}$ and Daniel Glossman-Mitnik ${ }^{\dagger *}$ \\ ${ }^{\dagger}$ Grupo NANOCOSMOS, Centro de Investigación en Materiales Avanzados, S.C., Miguel de Cervantes 120, Complejo \\ Industrial Chihuahua, Chih. 31109, México \\ ${ }^{\dagger}$ Centro de Investigación en Alimentación y Desarrollo, A.C. - Unidad Delicias, Av. 4ta. Sur 3820, Fracc. Vencedores \\ del Desierto, Cd. Delicias, Chih. 33089, México
}

\begin{abstract}
A theoretical study on the effects of a moderate amount of sulfur when used as substituent impurity in place of oxygen in zinc oxide at its crystal form using Density Functional Theory (DFT). S-substituent amounts in percent go from $0.1 \%$ up to $1.0 \%$ and we analyze modifications in the crystal properties such as lattice characteristics, total energy, and gap energy. Lattice parameter $\mathbf{c}$ increased slightly as S-substituent percent increased, lattice parameter a had an opposite behavior because it decreased as the S-substituent increased and $\mathbf{c} / \mathbf{a}$ rate had ups and downs but with very slight variation between consecutive values. Total energy calculations showed an increasing trend at all times and binding energy showed a decreasing trend at all times as the substituent percent increase but the variation between consecutive points was small. Gap energy had a decreasing trend with a maximum variation of $6.57 \%$ at $1.0 \% \mathrm{~S}$-substituent from pristine $\mathrm{ZnO}$. To correct DFT underestimation of gap energy we applied a correction factor and found a decreasing trend as the substituent percent increase and observed the highest difference from undoped $\mathrm{ZnO}$ was $1.42 \%$ at $1.0 \% \mathrm{~S}$-substituent. We study the effects on the $\mathrm{ZnO}$ structure occurring when moderate $\mathrm{S}$-substituent amounts from $0.1 \%$ to $1.0 \%$ are used and provide new knowledge to predict if the geometric and electronic structure changes may be suitable for new applications of $\mathrm{ZnO}$ in opto-electronics.
\end{abstract}

Keywords: Zinc oxide, sulfur, substitutional impurity, DFT, lattice, energy, gap energy.

\section{INTRODUCTION}

Zinc oxide $(\mathrm{ZnO})$ is a material with a wide array of applications and potential for applications in future technologies. Besides of merely using the bulk, the interest in quantum size effects has increased, especially because expertise in synthesizing $\mathrm{ZnO}$ nanowires both by vacuum $[1,2]$ and solution-based [3-5] methods has multiplied. Also, despite of $\mathrm{ZnO}$ band gap $(3.37 \mathrm{eV})$ is too large for use in efficient photovoltaic devices [6], attempts have been done to construct photovoltaics devices with schemes such as n-ZnO/p-CdTe thin film heterojunctions [7,8], $\mathrm{ZnO} / \mathrm{CdSe}$ composites [9], $\mathrm{n}-\mathrm{ZnO} / \mathrm{p}-\mathrm{Cu}_{2} \mathrm{O}$ heterojunctions $[10,11], \mathrm{n}-\mathrm{ZnO} / \mathrm{p}-\mathrm{Si}$ heterostructures [12,13], ZnO-nanocrystal/organic-polymer hybrid photovoltaics [14-21] and, $\mathrm{ZnO}$-nanocolumns as electrodes for dye-sensitized photoelectrochemical cells [22]. Siliconbased photovoltaics are limited by the high cost and energy input required to create the highly purified. Relying on toxic and somewhat less abundant $\mathrm{CdTe}$ and $\mathrm{CdSe}$, and organic photovoltaics suffer from low efficiency and short operating lifetimes (due to oxidative damage to the polymers), respectively [23]. A variety of experimental methods for partial

*Address correspondence to this author at the Centro de Investigación en Materiales Avanzados, SC, Departamento de Simulación Computacional y Modelado Molecular, Miguel de Cervantes 120 - Comp. Ind. Chihuahua Chihuahua, Chih 31109, Mexico; Tel: +52 614 4391151; Secretary/Fax: +52 614 4391130; Lab: +52 6144394805 ;

E-mails: daniel.glossman@cimav.edu.mx \& dglossman@gmail.com conversion of $\mathrm{ZnO}$ nanowires into $\mathrm{ZnO} / \mathrm{ZnS}$ core/shell nanowires [24-30] which are non-toxic and common materials in nature.

In the other hand, much attention has been drawn to polymer solar cells for their advantages in low cost and light weight compared to traditional solar cells [31-33]. However, it has been proposed that light absorption within these thin layers can be increased by changing the spatial distribution of the optical electric field inside the device [34,35]. The use of $\mathrm{TiO}_{2}$ as an optical spacer has been reported before [34]; $\mathrm{ZnO}$ is known to have similar characteristics than $\mathrm{TiO}_{2}$. In addition, Gilot et al. [36] presented theoretical and experimental results assessing the origin of the increased current in P3HT:PCBM solar cells with a $\mathrm{ZnO}$ spacer layer. According to Wo et al. [37] transparent conducting oxide (TCO) layers are suitable to be used as front electrodes in thin film solar cells $[38,39]$. $\mathrm{ZnO}$ has also been used as a sensor for hydrogen and carbon hydrides since the conductivity of thin zinc oxide films varies considerably with hydrogen gas pressure [40-42].

References within this section prove that $\mathrm{ZnO}$ is an interesting material for study and its potential is increased with the fact that combining a base material with small amounts of a different material can modify the base material properties; this option widens the possibilities of zinc oxide $(\mathrm{ZnO})$ for new applications. In semiconductors, such technique is commonly used to achieve a modification in the opto- 
electronic properties [43-45] and several teams have been working on improving such characteristics as well as other features like conductive and magnetic properties by using impurities in different percents and locations [46-48].

Our study relates to the effects of substitutional impurities on the $\mathrm{ZnO}$ opto-electronic properties, topic that has been raising interest lately no only in $\mathrm{ZnO}$ but also in other materials [49-54]. In this work we focused on $\mathrm{ZnO}$ due to its great potential in opto-electronic applications which have increased remarkably in latest years [55]. We use substitutional impurities as a technique to modify $\mathrm{ZnO}$ characteristics by reducing the gap energy and positively affect related properties [56,57]. We developed a theoretical study using Computational Chemistry and Density Functional Theory (DFT). Recently sulfur has been used as an impurity added to $\mathrm{ZnO}$ nanoforms [51,52] with good results but, there are few studies available related to such combination of materials and that is one of the reasons to use sulfur as the combining material in this work.

We develop an analysis on a $\mathrm{ZnO}$ crystal with $\mathrm{S}$ as a substituent of $\mathrm{O}$ at different percents that go from $0.1 \%$ to $1.0 \%$ which represents a moderate impurity proportion. Sulfur replaces the $\mathrm{O}$ in $\mathrm{ZnO}$ in its wurtzite form which is the $\mathrm{ZnO}$ more usual presentation in nature. We analyzed the lattice parameters, total energies, binding energies, and gap energy, then adjusted the data by means of a regression and analyzed the trends. Our study enhances the understanding of the effects in crystal $\mathrm{ZnO}$ when sulfur is used as a substitutional impurity. This work provides additional knowledge to quantify the effects of $\mathrm{S}$ in substitution of $\mathrm{O}$ in the crystal structure of $\mathrm{ZnO}$, such knowledge will help estimate in advance, using a theoretical perspective, the expected modification of electronic properties and if the modified semiconductor is suitable for a particular application.

\section{THEORY AND COMPUTATIONAL DETAILS}

Calculations were performed using Density Functional Theory (DFT) with the generalized gradient approximation (GGA) [58,59] and the corrected exchange-correlation by Perdew-Burke-Ernzerhof (PBE) [60] as implemented in the computer program Cambridge Serial Total Energy Package (CASTEP) [61-63]. Pseudopotentials with the plane-wave total energy [64-66] were employed. The self-consistent total energy in the ground state was effectively obtained by the density-mixed scheme [67]. Atomic positions were optimized by minimizing the total energy using the quasiNewton method with the Broyden-Fletcher-Goldfarb-Shanno Hessian scheme (BFGS) [68]. Ultrasoft pseudopotentials $[64,65]$ were employed to treat core electrons. CASTEP works with periodic systems by considering the contents of only a single repeat unit (unit cell), interactions with the virtually equivalent cells are described with mathematical techniques as implemented in CASTEP [63]. For all calculations, we used a single $\mathrm{ZnO}$ crystal unit cell in its wurtzite form with lattice parameters of $3.2493 \AA$ for $\mathbf{a}$, and $5.2054 \AA$ for $\mathbf{c}$ with a 9x9x6 k-point mesh. We created a $\mathrm{ZnO}$ crystal for each percent level and we applied $\mathrm{S}$ in substitution of $\mathrm{O}$ using substitution levels from $0.1 \%$ to $1.0 \%$ based in the atom count. For each structure, we applied the BFGS method to make the geometry optimization and using the optimized structure we made energy calculations to obtain the effects of
S-substituent in the $\mathrm{ZnO}$ structure. To compare stability we calculated the binding energy/atom (BE/atom) to identify the most stable cluster which is calculated from the next equation:

$\mathrm{BE} /$ atom $=\mathrm{nE}(\mathrm{Zn})+\mathrm{mE}(\mathrm{O})+\mathrm{p} * \mathrm{E}(\mathrm{S})-\mathrm{E}_{\mathrm{T}}(\mathrm{ZnO}) / \mathrm{n}+\mathrm{m}+\mathrm{p}$

where $\mathrm{E}(\mathrm{Zn}), \mathrm{E}(\mathrm{O}), \mathrm{E}(\mathrm{S})$ and $\mathrm{E}(\mathrm{ZnO})_{\mathrm{n}}$ are the total energies of the $\mathrm{Zn}$ atom, $\mathrm{O}$ atom, $\mathrm{S}$ atom and $\mathrm{E}_{\mathrm{T}}(\mathrm{ZnO})$ is the total energy of our $(\mathrm{ZnO})$ structure; all structures within this work are built with common characteristics except by the substituent content, in this way, $\mathrm{n}$ corresponds to the number of $\mathrm{Zn}$ atoms, $\mathrm{m}$ corresponds to the number of $\mathrm{O}$ atoms and $\mathrm{p}$ corresponds to the number of $\mathrm{S}$ atoms within the structure. For our GGA calculation of gap energy we used a correction technique known as the scissors operator [69,70] and obtained a better approximation to the real gap energy.

\section{RESULTS AND DISCUSSION}

\subsection{Lattice Parameters}

Lattice parameters $\mathbf{a}-\mathbf{b}, \mathbf{c}$ and rate $\mathbf{c} / \mathbf{a}$ for pure $\mathrm{ZnO}$ calculated with the method described in the prior section resulted on $3.2989 \AA$ for $\mathbf{a}, 5.30221 \AA$ for $\mathbf{c}$ and $1.6073 \AA$ for $\mathbf{c} / \mathbf{a}$ rate. These results are considered acceptable since they are in good agreement with the reported parameters from experimental and theoretical works which are $3.2488 \AA$ for $\mathbf{a}$, $5.20585 \AA$ for $\mathbf{c}$ and $1.633 \AA$ for c/a [71]. Size for parameter $\mathbf{b}$ is the same than size for parameter a at all times and for simplification in the next pages we will mention only parameter a. We calculated a $1.5 \%$ error for parameter $\mathbf{a}, 1.9 \%$ for parameter $\mathbf{c}$ and $0.78 \%$ for c/a rate. This error is low and confirms our calculations and method have acceptable accuracy. The same method was used for the optimized geometry calculations made in our $\mathrm{ZnO}$ structures when $\mathrm{S}$ was used as a substituent of $\mathrm{O}$ using different percentages from $0.1 \%$ until $1.0 \%$.

The results for the geometry optimization for lattice parameters a, $\mathbf{c}$ and $\mathbf{c} / \mathbf{a}$ are shown at Table 1. Results for parameters $\mathbf{a}, \mathbf{c}$, and $\mathbf{a} / \mathbf{c}$ rate showed a sligthly increasing trend as the S-substituent percent increases. The data points for latice parameters $\mathbf{a}, \mathbf{c}$ and $\mathbf{c} / \mathbf{a}$ rate were adjusted by means of a linear regression giving the next equations; $y=0.3835 \mathrm{x}+$ 3.2926 for parameter $\mathbf{a}, \mathrm{y}=1.7648 \mathrm{x}+5.3053$ for parameter $\mathbf{c}$ and $\mathrm{y}=0.3475 \mathrm{x}+1.6113$ for $\mathbf{c} / \mathbf{a}$ rate, with $x$ as the independent variable for the S-substituent percent and $y$ as the dependent variable in Amstrong ( $\AA$ ) for the lattice parameter length. All three equations have a positive slope value which indicates the increasing trend noted before. The equation for parameter a shows a slightly higher slope value but not too high, which indicates slightly bigger changes from point to point as the S-substituent percent increases. In this work we report a growing trend on lattice parameters as the substituent percent increases which is in disagreement with the work by Kar et al. [72]. In their work, they used $\mathrm{ZnO} / \mathrm{ZnS}$ heterostructures and reported a lattice decrease for zinc blende $\mathrm{ZnO}$ from $4.6 \AA$ to $2.61 \AA$. Regression on data points per our calculations on $\mathrm{ZnO}$ with $\mathrm{S}$ as substituent show a positive slope which indicates an increasing trend as the S-substituent increases but, even though lattice parameters had overall a growing trend, such trend was not effective for consecutive points at all times. Actually, lattice parameter c increased slightly as S-substituent percent increased but lattice parame- 
Table 1. Results for Lattice Parameters a/b, c, c/a, and Total Energy as Calculated in CASTEP.

\begin{tabular}{|c|c|c|c|c|c|c|}
\hline S (\%) & $\mathbf{a}, \mathbf{b}(\AA)$ & c $(\AA)$ & $\mathbf{c} / \mathbf{a}$ & $\begin{array}{c}\text { Formation Energy } \\
(\mathrm{eV})\end{array}$ & $\begin{array}{c}\text { Total Energy } \\
\text { Differences in \% }\end{array}$ & $\begin{array}{c}\text { Total Energy } \\
\text { Delta in } \%\end{array}$ \\
\hline Ref & $3.2488^{\mathrm{a}}$ & $5.2059^{\mathrm{a}}$ & $1.6330^{\mathrm{a}}$ & -- & -- & -- \\
\hline $0 \%$ & 3.2989 & 5.3022 & 1.6073 & -4294.6 & -- & -- \\
\hline $0.1 \%$ & 3.2895 & 5.3117 & 1.6148 & -4294.1 & $-0.0099 \%$ & $-0.0099 \%$ \\
\hline $0.3 \%$ & 3.2930 & 5.3086 & 1.6121 & -4293.3 & $-0.0292 \%$ & $-0.0097 \%$ \\
\hline $0.4 \%$ & 3.2928 & 5.3138 & 1.6138 & -4292.9 & $-0.0389 \%$ & $-0.0097 \%$ \\
\hline $0.5 \%$ & 3.2919 & 5.3191 & 1.6158 & -4292.5 & $-0.0486 \%$ & $-0.0097 \%$ \\
\hline $0.6 \%$ & 3.2940 & 5.3183 & 1.6145 & -4292.1 & $-0.0583 \%$ & $-0.0096 \%$ \\
\hline $0.9 \%$ & 3.2985 & 5.3160 & 1.6116 & -4290.8 & $-0.0873 \%$ & $-0.0097 \%$ \\
\hline $1.0 \%$ & 3.2971 & 5.3232 & 1.6145 & -4290.4 & $-0.0970 \%$ & $-0.0097 \%$ \\
\hline
\end{tabular}

${ }^{\text {a }}$ Reference lattice parameters from experimental and theoretical works [71].

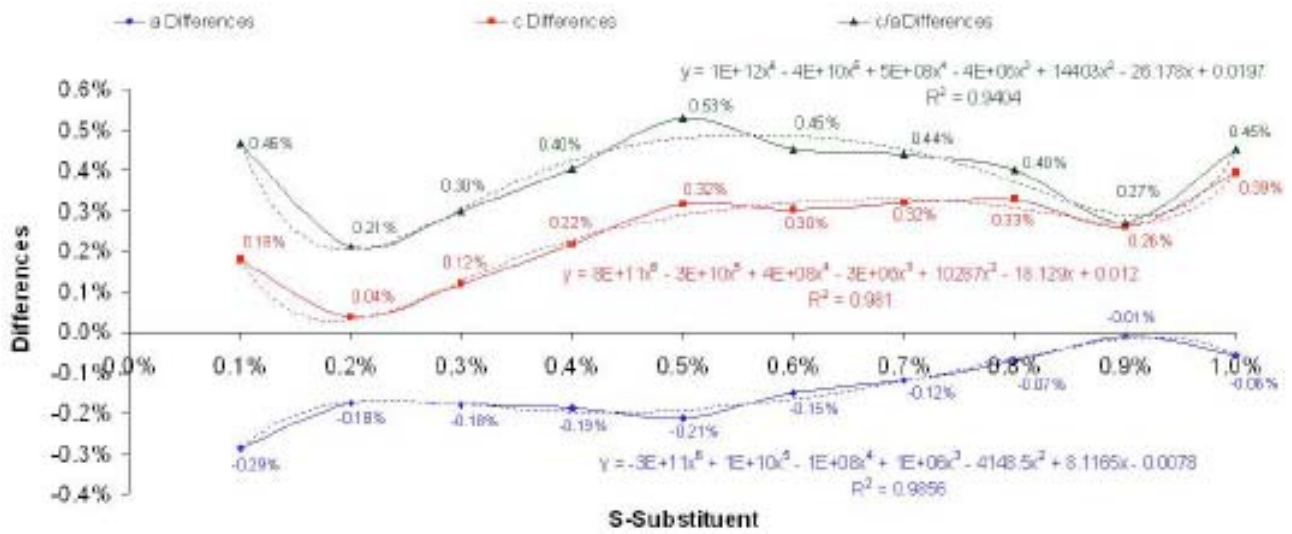

Fig. (1). Differences for Lattice Parameters (DLP) in percent for ZnO crystal structure with S as substituent.

ter a behavior was the opposite because it decreased as the Ssubstituent increased.

We analyzed how much lattice parameters changed with respect to pristine $\mathrm{ZnO}$. To do this, we made a simple calculation called differences (D) through this document. So when we refer to the differences in this paper means the value showed as a percentage was found by using the next arithmetic equation:

$$
\left(D L P_{a} 0.2 \% S\right)=\frac{\left[\left(L P_{a} 0.2 \% S\right)-\left(L P_{a} \text { pure }\right)\right]}{\left(L P_{a} 0.2 \% S\right)} \times 100
$$

Where $\mathrm{D}=$ difference in percent, $\mathrm{LP}_{\mathrm{a}}=$ lattice parameter $\mathbf{a}$, $0.2 \% \mathrm{~S}=$ for $0.2 \% \mathrm{~S}$ as example only; it will vary according to the substituent content $(0.1 \%-1 \%)$.

Instead of the arithmetic difference we used percents of change in our analysis for the lattice differences calculated for each S-substituent level. For the analysis of differences we used our results from GGA calculations for pure $\mathrm{ZnO}$ and structures with S-substituent so all the values compared are consistent with the same geometry optimization method. We used the simple equation showed previously for analyzing parameter a results when $\mathrm{ZnO}$ was in its pristine form as well as for the case when $\mathrm{S}$ was added into $\mathrm{ZnO}$. The same methodology was used to calculate the differences for parameter $\mathbf{c}$ and $\mathbf{c} / \mathbf{a}$ rate.

Parameter a DLP data points were graphed and showed a non-linear curve which we adjusted to the $6^{\text {th }}$ power equation:

$$
\begin{aligned}
& y=-3 x 10^{11} x^{6}+1 \times 10^{10} x^{5}-1 x 10^{8} x^{4}+1 \times 10^{6} x^{3} \\
& -4148.5 x^{2}+8.1165 x-0.0078
\end{aligned}
$$

Parameter a decreased when compared to pure $\mathrm{ZnO}$ and the smaller value for lattice parameter a was $-0.29 \%$ and was observed at $0.1 \% \mathrm{~S}$-substituent. On the other hand, the higher value for lattice parameter a was $-0.01 \%$ and was observed at $0.9 \%$ S-substituent level. Overall the differences 


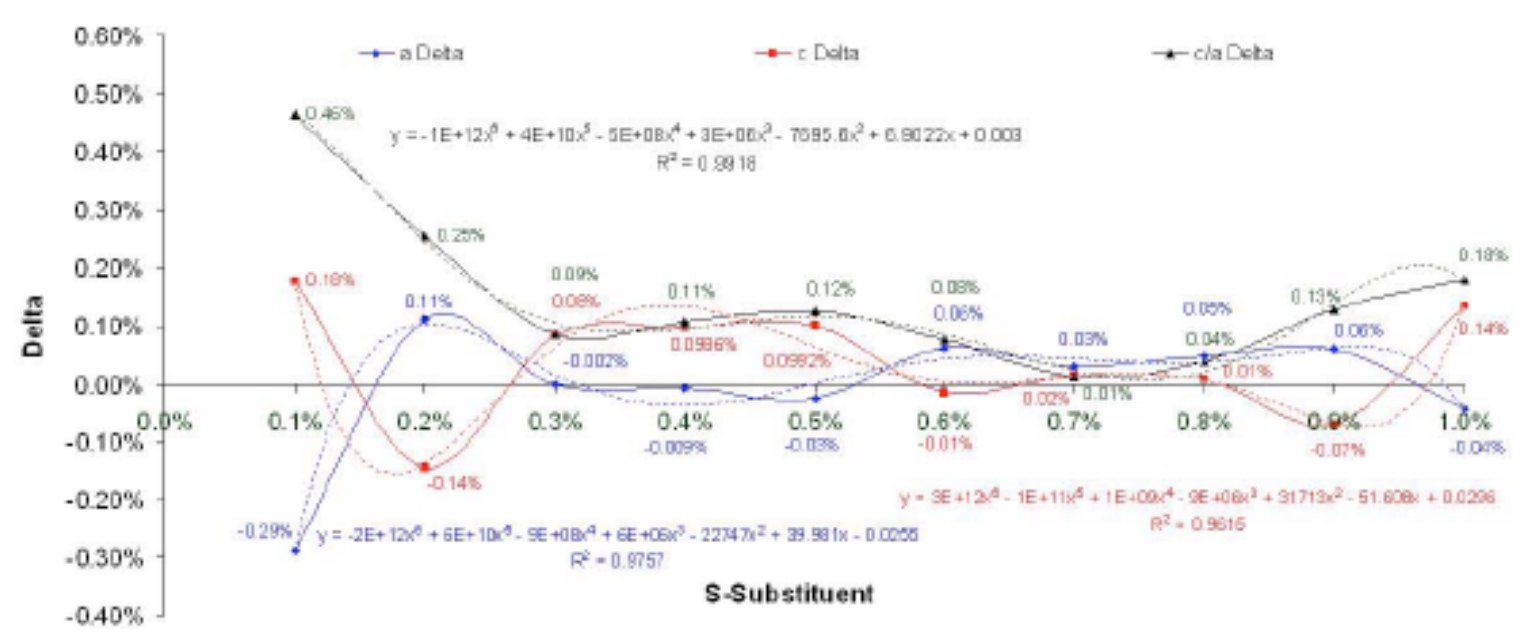

Fig. (2). Delta Rate in percent for Lattice Parameters (DRLP) of $\mathrm{ZnO}$ crystal structure with $\mathrm{S}$ as substituent.

were negative values, this means that all calculated values for S-susbtituted $\mathrm{ZnO}$ had lattice parameter a smaller that the one for pure $\mathrm{ZnO}$. After the first S-substitution at $0.1 \%$, parameter a grew in a total of five data points $(0.2 \%, 0.6 \%$, $0.7 \%, 0.8 \%$ and $0.9 \% \mathrm{~S}$-substituent), one S-substituent data point remained without variation $(0.3 \% \mathrm{~S}$-substituent $)$ and three data points increased $(0.4 \%, 0.5 \%$ and $1.0 \% \mathrm{~S}$ substituent).

Differences for parameter $\mathbf{c}$ had positive values, which means parameter c grew every time the S-substituent was present in the $\mathrm{ZnO}$ structure. The lower difference value found was $0.04 \%$ observed at $0.2 \% \mathrm{~S}$-substituent and in the other hand, the higher difference value was $0.39 \%$ observed at $1 \% \mathrm{~S}$-substituent. Parameter $\mathbf{c}$ data points were adjusted by means of a regression and obtained a $6^{\text {th }}$ power equation as shown below:

$$
\begin{aligned}
& y=8 x 10^{11} x^{6}-3 \times 10^{10} x^{5}+4 \times 10^{8} x^{4}-3 \times 10^{6} x^{3} \\
& +10287 x^{2}-18.129 x+0.012
\end{aligned}
$$

For parameter $\mathbf{c}$, seven data points showed a growing trend at $0.1 \%, 0.3 \%, 0.4 \%, 0.5 \%, 0.7 \%, 0.8 \%$ and $1.0 \% \mathrm{~S}-$ substituent and other three data points had a decreasing trend. Differences for c/a rate have a very similar behavior than parameter c. That means, all data points are positive which indicate c/a rate grew at all times on structures containing S-substituent with respect to the case of pristine $\mathrm{ZnO}$. We fitted c/a rate data points by means of a regression and found a $6^{\text {th }}$ power curve equation as shown next:

$$
\begin{aligned}
& y=1 \times 10^{12} x^{6}-4 x 10^{10} x^{5}+5 \times 10^{8} x^{4}-4 \times 10^{6} x^{3} \\
& +14403 x^{2}-26.178 x+0.0197
\end{aligned}
$$

The equation for c/a rate is very similar to the equation for parameter $\mathbf{c}$ and, in a similar way the curve for $\mathbf{c} / \mathbf{a}$ rate has a similar shape than the curve for parameter c. From there, five data points showed an increasing trend at $0.1 \%$, $0.3 \%, 0.4 \%, 0.5 \%$ and $1.0 \%$ S-substituent. In contrast, five data points showed a decreasing trend at $0.2 \%, 0.6 \%, 0.7 \%$, $0.8 \%$ and $0.9 \%$ S-substituent. Fig. (1), shows the data points and regression curves for the calculated differences in lattice parameters.
To find the change in lattice length from one substituent percent data point to the prior percent data point we did a simple calculation by subtracting the lattice parameter from the prior substituent level to the current percent level as shown in the next arithmetic equation. The next calculation shows an example of what we denominated as delta rate calculation (DR) which when applied on lattice parameters we will call it DRLP as follows:

$$
\left(D R L P_{a} 0.2 \% S\right)=\frac{\left[\left(L P_{a} 0.2 \% S\right)-\left(L P_{a} 0.1 \% S\right)\right]}{\left(L P_{a} 0.2 \% S\right)} \times 100
$$

Where $\mathrm{DR}=$ delta rate, $\mathrm{LP}_{\mathrm{a}}=$ lattice parameter $\mathbf{a}$ and $0.2 \%$ $\mathrm{S}=$ for $0.2 \% \mathrm{~S}$ as example only; it will vary according to the substituent content $(0.1 \%-1 \%)$.

We performed DR calculations for $\mathbf{a}, \mathbf{c}$ and $\mathbf{c} / \mathbf{a}$ parameters using results from the optimized geometry on the Ssubstituted crystal. When we did the DR calculation for lattice parameters we graphed the data points to find the trend and added a regression adjustment which was found to be non-linear. This simple calculation showed that the lattice had bigger changes at some substituent percents.

Calculated DRLP data points for parameter a were graphed and we applied a regression to fit the data points to a $6^{\text {th }}$ power equation as shown below:

$$
\begin{aligned}
& y=-3 x 10^{12} x^{6}+1 x 10^{10} x^{5}-1 \times 10^{8} x^{4}+1 \times 10^{6} x^{3} \\
& -4148.5 x^{2}+8.1165 x-0.0078
\end{aligned}
$$

The curve and the equation show that calculated DR for parameter a does not have a uniform behavior which means, as the S-substituent increases point after point parameter a grows in different proportions. Furthermore, DR for parameter a had five negative points which indicates, parameter a decreased in five points after the S-substituent proportion was increased. On the other hand, DR calculations for parameter a had five positive data points which indicates parameter a grew from one data point to the next consecutive data point in different occasions. It may be noticed that below a content of $0.5 \%$ S-substituent, four data points had negative DR values and only one had positive value, meanwhile, for those DR calculations at $0.6 \%$ or more S- 
substituent, four out of five DR calculations had positive values. DR calculations for parameter a had a bigger decreasing rate of $-0.29 \%$ at $0.1 \% \mathrm{~S}$-substituent and this point was also the bigger change observed in the application of Ssubstituent from $0.1 \%$ up to $1.0 \%$. The bigger growth rate was $0.11 \%$ observed at $0.2 \%$ S-substituent. All DR calculations for parameter a have slight variation, eight points showed to be in the second digit after the decimal point. Something notorious is that the bigger DR changes are observed at the lower S-substituent compounds $0.1 \%$ and $0.2 \%$ and after that the rest of the values show changes nearby zero either above or below.

Calculated DRLP data points for parameter c were graphed and we applied a regression to fit the data points to a $6^{\text {th }}$ power equation as shown below:

$$
\begin{aligned}
& y=3 \times 10^{12} x^{6}-1 \times 10^{11} x^{5}+1 \times 10^{9} x^{4}-9 \times 10^{6} x^{3} \\
& +31713 x^{2}-51.608 x+0.0296
\end{aligned}
$$

DRLP calculations for parameter $\mathbf{c}$ had seven positive points which indicates that most of the times such lattice parameter at a particular S-substituent percent, had a certain growth level from its predecesor. The other three points had negative values which indicate lattice parameter $\mathbf{c}$ reduced its size if compared with the previous S-substituent data point. The higher increment in size was $0.18 \%$ and it was observed at $0.1 \% \mathrm{~S}$-substituent. In contrast, the lower decrement in size was $-0.14 \%$ observed at $0.2 \%$ S-substituent. One relevant characteristic related to parameter $\mathbf{c}$, noticed at the DRLP curve, is the opposite trend behavior when compared to parameter a DRLP curve. This means that when DRLP for parameter $\mathbf{c}$ has an increasing trend, parameter a DRLP curve had a decreasing trend. For example, at $0.2 \% \mathrm{~S}$ substituent, DRLP for parameter a had an increasing trend because it came from $-0.29 \%$ and grew up to $0.11 \%$, and at the same time, DRLP for parameter $\mathbf{c}$ had a decreasing trend because it came from a $0.18 \%$ and it decreased down to $0.14 \%$.

Calculated DRLP data points for c/a rate were graphed and we applied a regression to fit the data points to a $6^{\text {th }}$ power equation as shown below:

$$
\begin{aligned}
& y=-1 \times 10^{12} x^{6}+4 \times 10^{10} x^{5}-5 \times 10^{8} x^{4}+3 \times 10^{6} x^{3} \\
& -7695.6 x^{2}+6.9022 x+0.003
\end{aligned}
$$

All ten data points calculated for c/a rate were positive values and the higher value calculated was $0.46 \%$ observed at $0.1 \% \mathrm{~S}$-substituent. The lower value was $0.01 \%$ observed at $0.7 \% \mathrm{~S}$-substituent. Delta rates and regression curves for each one derived from lattice parameters $\mathbf{a}, \mathbf{c}$, and $\mathbf{c} / \mathbf{a}$ can be seen at Fig. (2).

\subsection{Total Energy}

Total energy calculations were done starting from the optimized geometry. A total energy of $-4294.5590 \mathrm{eV}$ was calculated for pure $\mathrm{ZnO}$. Total energy calculations were fitted by means of linear regression and gave the next equation, $y=$ 415.44x - 4294.6. Total energy for each of the different substituent percent levels from $0.1 \%$ to $1.0 \%$ had an increasing trend indicating that as the substituent level increases the total energy increases. To quantify the total energy change we calculated the average for all calculated energy values which was $-4292.47 \mathrm{eV}$ with standard deviation of $1.38 \mathrm{eV}$. According to the standard deviation one can assume the variation value is too small if compared to the mean value or, in other words, $1.38 \mathrm{eV}$ represents only a $0.032 \%$ of the energy average value $-4292.47 \mathrm{eV}$ and such proportion is almost despicable. In addition, we calculated the differences using a similar equation to the one used for lattice parameters. The next equation was used to calculate total energy differences:

$$
\left(D T E_{-} 0.2 \% S\right)=\frac{\left[\left(T E_{-} 0.2 \% S\right)-\left(T E_{-} \text {pureZnO }\right)\right]}{\left(T E_{-} 0.2 \% S\right)} \times 100
$$

Where $\mathrm{D}=$ difference in percent, $\mathrm{TE}=$ total energy and $0.2 \%$ $\mathrm{S}=$ for $0.2 \% \mathrm{~S}$ as example only; it will vary according to the substituent content $(0.1 \%-1 \%)$.

With this equation we calculated the differences from the total energy results at each S-substituent percent level and made a linear regression to find the fitting equation $y=-0.0967 x-2 x 10^{6}$, where $x$ is the independent variable indicating the S-susbstituent percent and $y$ is the dependent variable indicating the difference in percent. Calculations for differences show an increasing trend for the total energy as the substituent is increased. Also, we calculated the delta rates for total energy using a similar equation than the one used in the DR calculation for lattice parameters, the equation is as follows:

$$
(\text { DRTE } 0.2 \% S)=\frac{[(T E 0.2 \% S)-(T E 0.1 \% S)]}{(T E 0.2 \% S)} \times 100
$$

Where $\mathrm{DR}=$ delta rate, $\mathrm{TE}=$ total energy and $0.2 \% \mathrm{~S}=$ for $0.2 \% \mathrm{~S}$ as example only; it will vary according to the substituent content $(0.1 \%-1 \%)$.

For the delta rate values calculated for total energies we fitted the data points to a linear regression and found the next equation $y=0.0001 x-1 \times 10^{-4}$. The 0.0001 value indicates the curve slope and means a trend with a slope value near zero. Such trend indicates The 0.0001 slope value is near zero which indicates an almost uniform behaviour from DR values, that means, the growing is very similar point after point as the S-substituent increases. Total energy results, differences and delta rates calculations are shown at Table $\mathbf{1}$.

Results for total energy indicate an increasing trend as the substituent increases, we calculated the binding energy (BE) by atom to verify the structure stability behavior and found a linear trend indicating the stability decreases as the substituent amount increases. BE data points were graphed and fitted to a curve by means of a linear regression and obtained the equation $y=-26.049 x+4.5108$. Fig. (3) shows the graph for $\mathrm{BE}$ as well as the values found for each structure including both cases, $\mathrm{ZnO}$ at its pristine form and after substitution.

\subsection{Gap Energy}

Gap energy $\left(E_{g}\right)$ calculations resulted on $0.731 \mathrm{eV}$ for pure $\mathrm{ZnO}$ which is in good agreement with the $0.735 \mathrm{eV}$ reported by other GGA calculations [55]. Our GGA calcula- 


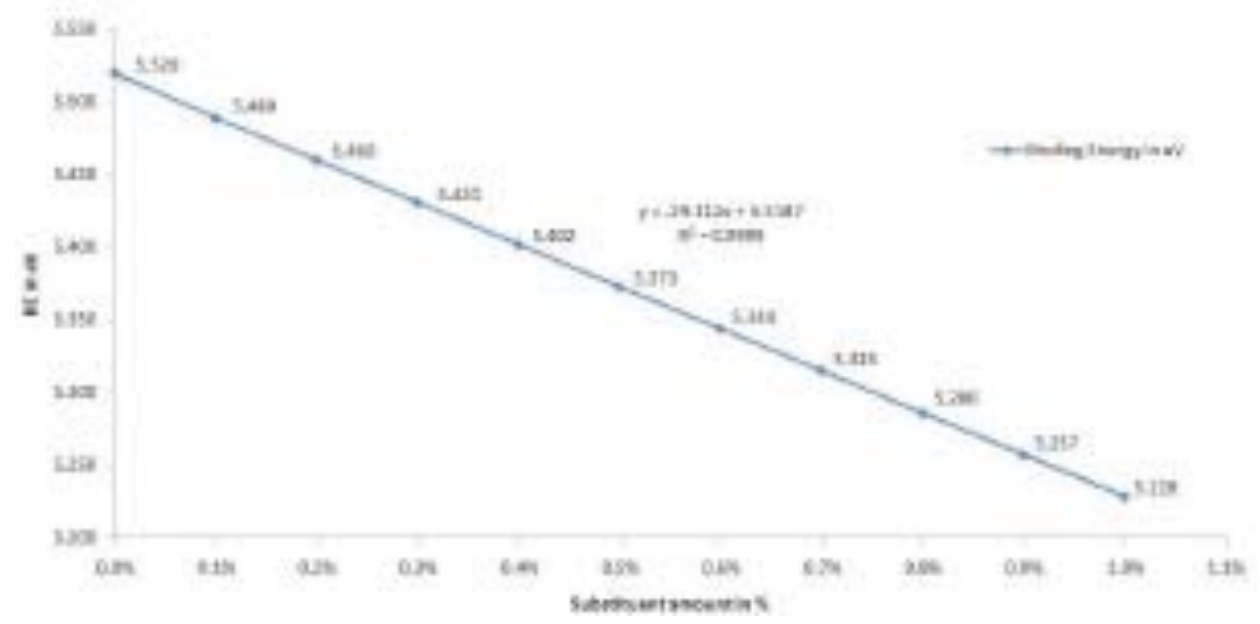

Fig. (3). Binding energy in eV shown for all structures including both cases, $\mathrm{ZnO}$ at its pristine form and after substitution. Horizontal axis shows the substituent amount in percent.

Table 2. Gap Energy, $\mathrm{DE}_{\mathrm{g}}$ and $\mathrm{DRE}_{\mathrm{g}}$ from GGA Calculations and after Application of Scissors Factor

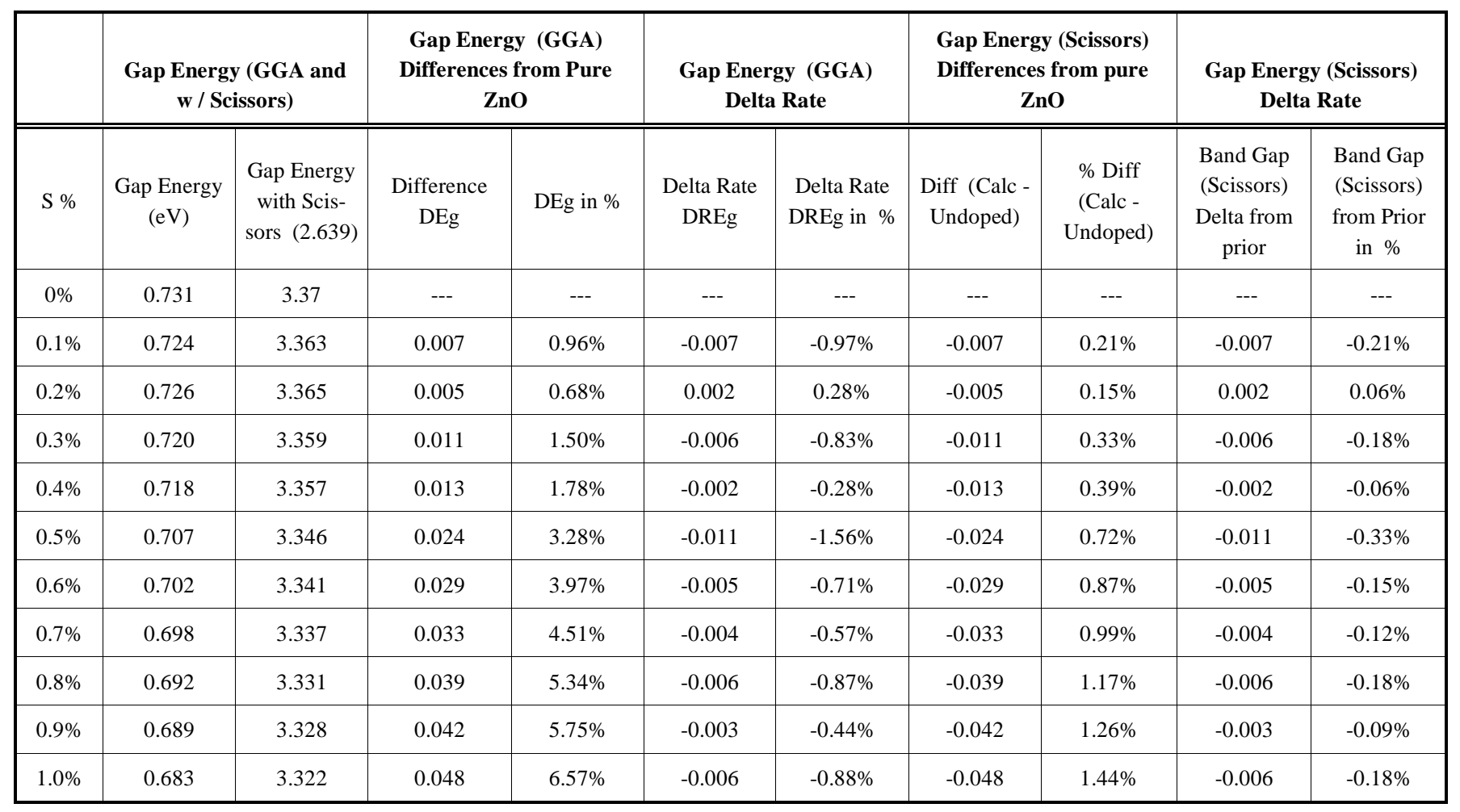

tions for $\mathrm{ZnO}$ at its pristine form give a $0.54 \%$ deviation from GGA referential works and for that reason we considered our method acceptable. Since DFT methods under estimate $\mathrm{E}_{\mathrm{g}}$ we used the scissors technique to apply a correction factor. We will present an analysis of trends for the results in $\mathrm{S}$ - substituted $\mathrm{ZnO} \mathrm{E}_{\mathrm{g}}$, for its differences and delta rates. As a general rule our analysis will be separated on two sets of comments, the first comments will be based on $E_{g}$ from GGA results while the second will be based on $\mathrm{E}_{\mathrm{g}}$ from corrected values using the scissors factor.

In sum, we will present first a trend analysis of Eg results when used GGA values which will include an analysis for the corrected values, second a trend analysis of S-substituted differences with pure gap energy using GGA which will include its corresponding analysis for corrected values and third an analysis over the delta rates to find the change rate to the prior S-substituent percent level for GGA results which will include the analysis for corrected values.

For our results on $\mathrm{E}_{\mathrm{g}}$ we observed the $\mathrm{E}_{\mathrm{g}}$ trend decreases as the substituent level increases. The lowest value found is $0.683 \mathrm{eV}$ at $1.0 \% \mathrm{~S}$-substituent and represents a $6.57 \%$ change from pure $\mathrm{ZnO}$. The linear regression for $\mathrm{E}_{\mathrm{g}}$ on $\mathrm{GGA}$ calculations resulted in the equation: $y=-4.9273 x+0.7328$. After applying the scissors technique $\mathrm{E}_{\mathrm{g}}$ values were fitted to a curve by means of regression and we found a linear equation: $\mathrm{y}=-4.9273 \mathrm{x}+3.3718$. The lowest $\mathrm{E}_{\mathrm{g}}$ value was 3.322 
$\mathrm{eV}$ observed at $1.0 \% \mathrm{~S}$-substituent which represents $1.42 \%$ change from pure $\mathrm{ZnO}$. One can note both equations do have the same slope value of -4.9273 . Results from GGA calculations for $E_{g}$ and scissors corrected $E_{g}$ values are shown at Table 2 and regression curve at Fig. (3).

We did calculations for the $\mathrm{E}_{\mathrm{g}}$ differences $\left(\mathrm{DE}_{\mathrm{g}}\right)$ between the $\mathrm{S}$-substituted $\mathrm{E}_{\mathrm{g}}$ compared with the pure case using percents as the unit to measure the change. To calculate the differences, we used an arithmetic equation similar to the equation used to calculate the differences in lattice parameters (DLP). The differences for $\mathrm{E}_{\mathrm{g}}$ will be called $\mathrm{DE}_{\mathrm{g}}$ in the equation as shown below:

$$
D E_{g} 0.2 \% S=A b s\left[\frac{\left(E_{g} 0.2 \% S\right)-\left(E_{g} \text { pureZnO }\right)}{\left(E_{g} 0.2 \% S\right)} \times 100\right]
$$

Where Abs= absolute value, $\mathrm{D}=$ difference, $\mathrm{E}_{\mathrm{g}}=$ gap energy and $0.2 \% \mathrm{~S}=$ for $0.2 \% \mathrm{~S}$ as example only; it will vary according to the substituent content $(0.1 \%-1 \%)$.

Our results indicate $\mathrm{E}_{\mathrm{g}}$ has an increasing trend for differences as shown in Fig. (4). That means that as the Ssubstituent was increased $\mathrm{E}_{\mathrm{g}}$ difference from pure $\mathrm{ZnO}$ increased as well. The higher value for $\mathrm{E}_{\mathrm{g}}$ differences was $6.57 \%$ observed at $1.0 \%$ S-substituent. The trend for $\mathrm{DE}_{\mathrm{g}}$ data points from GGA calculations were fitted to a curve with a regression that gave a $6^{\text {th }}$ power equation as shown below:

$$
\begin{aligned}
& y=512 x^{6}+1 x 10^{9} x^{5}+1 x 10^{7} x^{4}-698185 x^{3} \\
& +7174.8 x^{2}-18.565 x+0.0215
\end{aligned}
$$

For $\mathrm{DE}_{\mathrm{g}}$ using scissors corrected values we found a higher value of $1.44 \%$ at $1.0 \%$ S-substituent. For $D_{g}$ values from scissors corrected calculations we made a regression to obtain the next $6^{\text {th }}$ power equation to describe its behavior:

$$
\begin{aligned}
& y=2 \times 10^{8} x^{6}+2 \times 10^{9} x^{5}+2 \times 10^{6} x^{4}-146010 x^{3} \\
& +1539.3 x^{2}-4.007 x+0.0047
\end{aligned}
$$

One can notice that after scissors technique was applied corrected $\mathrm{DE}_{\mathrm{g}}$ values had the same trend than the curve for $\mathrm{DE}_{\mathrm{g}}$ from GGA calculations; GGA results had a more pronounced steep and that is the reason for a smaller $D_{\mathrm{g}}$ value at the highest S-substituent percent. $\mathrm{DE}_{\mathrm{g}}$ results for both
GGA calculations and scissors corrected calculations are shown in Table 2.

In addition we analyzed $\mathrm{E}_{\mathrm{g}}$ delta change that exists between the current $\mathrm{S}$-substituent percent and the prior substituent percent level for both GGA results and scissors corrected $\mathrm{E}_{\mathrm{g}}$ values. We used an arithmetic equation similar to the one used for calculation of delta rate for lattice parameters (DRLP). The delta rates for $\mathrm{E}_{\mathrm{g}}$ are also called $\mathrm{DRE}_{\mathrm{g}}$ in the equation as shown below:

$$
A b s\left(D R E_{g} 0.2 \% S\right)=A b s\left[\frac{\left(E_{g} 0.2 \% S\right)-\left(E_{g} 0.1 \% S\right)}{\left(E_{g} 0.2 \% S\right)}\right] \times 100
$$

Where $\mathrm{Abs}=$ absolute, $\mathrm{DR}=$ delta rate, $\mathrm{E}_{\mathrm{g}}=$ gap energy and $0.2 \% \mathrm{~S}=$ for $0.2 \% \mathrm{~S}$ as example only; it will vary according to the substituent content $(0.1 \%-1 \%)$.

For DRE $_{\mathrm{g}}$ using GGA results we observed an iregular trend as the S-substituent increases as shown at Fig. (5). This means that despite $\mathrm{E}_{\mathrm{g}}$ showed an increasing trend in most of the S-substituent values, $\mathrm{DRE}_{\mathrm{g}}$ did not follow the same rule. In fact, both $\mathrm{DRE}_{\mathrm{g}}$ curves had ups and downs and in the curve from GGA calculations this behaviour is obvious. We performed a regression to adjust $\mathrm{DRE}_{\mathrm{g}}$ data points from GGA results and obtained an equation to the $6^{\text {th }}$ power as follows:

$$
\begin{aligned}
& y=-5 x 10^{12} x^{6}+2 x 10^{11} x^{5}-3 \times 10^{9} x^{4}+2 \times 10^{7} x^{3} \\
& -75388 x^{2}+132.6 x-0.0842
\end{aligned}
$$

The bigger change was $-1.56 \%$ observed at $0.5 \% \mathrm{~S}$ subsituent. Only one $\mathrm{DRE}_{\mathrm{g}}$ data point was a positive value and the other nine were negative values. The only positive value was the only one time in which the gap energy increased from one S-substituent percent to the next consecutive value but it is important to say that in spite of the gap energy increased from $0.1 \%$ to $0.2 \% \mathrm{~S}$-substituent, the gap energy value at $0.2 \% \mathrm{~S}$-substituent was smaller than the gap energy for pure $\mathrm{ZnO}$.

For $\mathrm{DRE}_{\mathrm{g}}$ from scissors calculations we fitted the data points to a curve by means of a regression and obtained an equation to the $6^{\text {th }}$ power as follows:

$$
\begin{aligned}
& y=-1 \times 10^{12} x^{6}+4 x 10^{10} x^{5}-6 x 10^{8} x^{4}+4 x 10^{6} x^{3} \\
& -16231 x^{2}+28.539 x-0.0181
\end{aligned}
$$

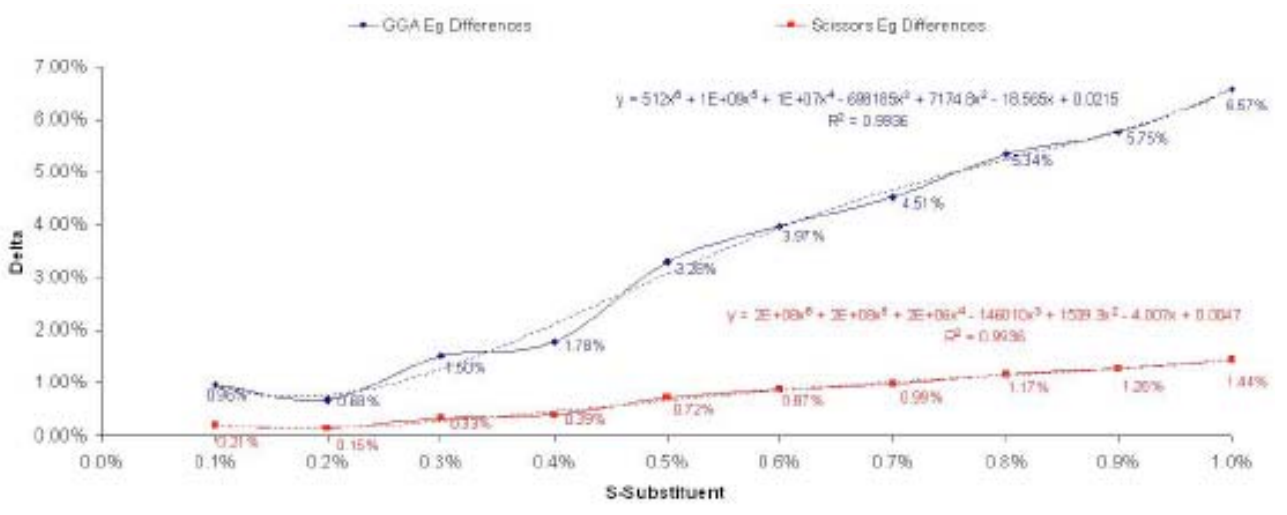

Fig. (4). Differences for Gap Energy ( $\left.\mathrm{DE}_{\mathrm{g}}\right)$ in percent for the $\mathrm{ZnO}$ crystal structure with $\mathrm{S}$ as substituent. 


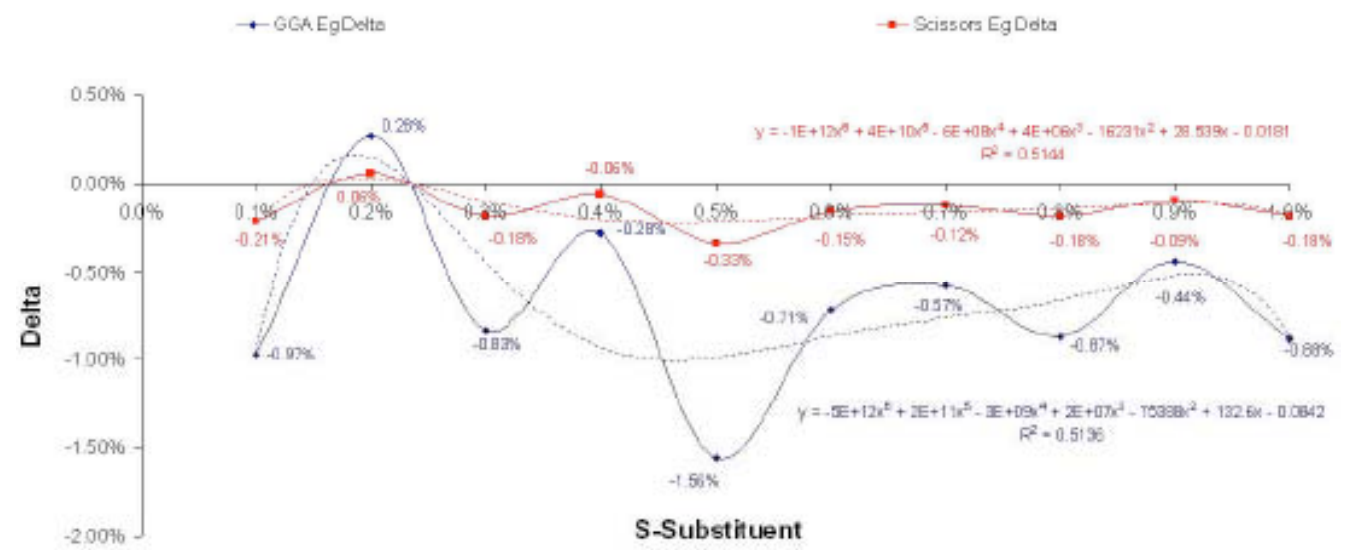

Fig. (5). Delta Rates for Gap Energy (DRE $\mathrm{g}_{\mathrm{g}}$ ) for the $\mathrm{ZnO}$ crystal structure with $\mathrm{S}$ as substituent using GGA calculated values and values after scissors technique application.

The bigger change on $\mathrm{DRE}_{\mathrm{g}}$ for scissors calculations was $-0.33 \%$ observed at $0.5 \% \mathrm{~S}$-subsituent. Only one $\mathrm{DRE}_{\mathrm{g}}$ data point had a positive value, meanwhile, the other nine were negative values and again, the negative value was the only one time in which the gap energy increased from one Ssubstituent percent to the next consecutive value. $\mathrm{DRE}_{\mathrm{g}}$ data points for both GGA results and scissors calculation are shown in Fig. (3).

$\mathrm{E}_{\mathrm{g}}$ decreasing trend for $\mathrm{S}$-substituted $\mathrm{ZnO}$ is in good agreement with reported studies which predict that as Ssubstituent percent increases $\mathrm{E}_{\mathrm{g}}$ decreases. Our contribution is the correlation between the $\mathrm{S}$ percent used on $\mathrm{ZnO}$ and the $\mathrm{E}_{\mathrm{g}}$ change on the modified crystal at moderate S-substituent amounts going from $0.1 \%$ to $1.0 \%$ which to the best of our knowledge has not been reported before. Even though, some studies confirm sulfur addition on $\mathrm{ZnO}$ reduces its gap energy, the values cannot be compared directly because the works are different in nature, for example, Schrier et al. [73] reported that the combination of $\mathrm{ZnO} / \mathrm{ZnS}$ had an $\mathrm{E}_{\mathrm{g}}$ shifting for $\mathrm{ZnO} / \mathrm{ZnS}$ bulk from $3.334 / 3.716 \mathrm{eV}$ to $2.614 / 3.494 \mathrm{eV}$ which represents a $22.2 \% \mathrm{E}_{\mathrm{g}}$ reduction from pure $\mathrm{ZnO}$ and this is in agreement with the $\mathrm{E}_{\mathrm{g}}$ reduction prediction made in the present work. Another example is a prior study made by our team in process of publication in which we used heavy amounts of S-substituent going from $1.0 \%$ to $10 \%$ in which we observed similar trends to those reported in this work.

\section{CONCLUSIONS}

In conclusion, lattice parameter $\mathbf{c}$ increased slightly as Ssubstituent percent increased but lattice parameter a decreased as the S-substituent increased and c/a rate had ups and downs but with slight variation between consecutive values. Equations were proposed as mathematical model for the changes experienced by lattice parameters when Ssubstituent was applied at consecutive percents from $0.1 \%$ to $1.0 \%$ with increments of $0.1 \%$; an equation to the $6^{\text {th }}$ power was obtained when structures with substitution were compared to pure $\mathrm{ZnO}$ and also an equation to the $6^{\text {th }}$ power was obtained for comparison between consecutive data points.

Total energy results showed an increasing trend at all times but the variation between consecutive points was very small. The regression for total energy was linear. Change in total energy is not too big when the substitution was applied and, together with the analysis of binding energy results, it is confirmed stability decreases as the substituent percent increases. Gap energy had a decreasing trend with a maximum variation of $6.57 \%$ at $1.0 \%$ S-substituent from pure $\mathrm{ZnO}$. When applied the scissors technique as a correction factor, it was observed a decreasing trend and showed a maximum variation of $1.42 \%$ at $1.0 \% \mathrm{~S}$-substituent from $\mathrm{ZnO}$ at its pristine from. Both regression equations for $\mathrm{E}_{\mathrm{g}}$ (from GGA results and after scissors correction) showed the same slope of -4.9273. Data points corresponding to $\mathrm{E}_{\mathrm{g}}$ differences between structures with substitution and pure $\mathrm{ZnO}$ fitted to an equation to the $6^{\text {th }}$ power. In addition, we proposed the expected change rate for $E_{\mathrm{g}}$ between consecutive S-substituent points and found an equation to the $6^{\text {th }}$ power as the best fitting. This study proposes particular effects do occur when used moderate amounts of $\mathrm{S}$ as substituent (from $0.1 \%$ to $1.0 \%$ ) because while parameter a decreases, parameter c increases as the substituent percent increases. Meanwhile, despite of $E_{\mathrm{g}}$ decrement was expected, this work adds deeper discussion on the expected changes for $\mathrm{E}_{\mathrm{g}}$ and proposes mathematical models for them.

As final comment, we found great potential for future developments related to substitution of $\mathrm{S}$ on $\mathrm{ZnO}$ which for a start could consider the use of different $\mathrm{ZnO}$ structures such as nanoclusters or nanotubes. Another future opportunity is to use over one hundred $\mathrm{ZnO}$ units for bulk studies which nowadays is a really difficult task for DFT studies due to computational cost and program capabilities but, future improvements in DFT methods or the use of different methodologies could make it possible and deeper knowledge, with increased similarity to reality, could be developed for the interaction between $\mathrm{ZnO}$ with $\mathrm{S}$ or other impurities.

\section{ACKNOWLEDGEMENTS}

This work has been partially supported by Consejo Nacional de Ciencia y Tecnología (CONACYT, Mexico) and by Fondo Mixto del Estado de Baja California through Grant $\mathrm{N}^{\circ}$ 69363. M.A.F.H. thanks for a doctoral scholarship granted by CONACYT. D.B.J. is a Researcher of CONACYT and CIAD. D.G.M. is a researcher of CONACYT and CIMAV. 


\section{REFERENCES}

[1] Goldberger, J.; Sirbuly, D.J.; Law, M.; Yang, P.J. Semiconductor nanowires for subwavelength photonics integration. Phys. Chem. B, 2005, 109, 15190 .

[2] Chang, P.C.; Chien, C.J.; Stichtenoth, D.; Ronning, C.; Lu, J.G. Finite size effect in $\mathrm{ZnO}$ nanowires. Appl. Phys. Lett., 2007, 90, 113101.

[3] Green, L.E.; Yuhas, B.D.; Law, M.; Zitoun, D.; Yang, P. SolutionGrown Zinc Oxide Nanowires. Inorg. Chem., 2006, 45, 7535.

[4] Anthony, S.P.; Lee, J.I.; Kim; J.K. Tuning optical band gap of vertically aligned $\mathrm{ZnO}$ nanowire arrays grown by homoepitaxial electrodeposition. Appl. Phys. Lett., 2007, 90, 103107.

[5] Liu, J.; Huang, X.; Li, Y.; Ji, X.; Li, Z.; He, X.; Sun, F.J. Vertically Aligned 1D ZnO Nanostructures on Bulk Alloy Substrates: Direct Solution Synthesis, Photoluminescence, and Field Emission. Phys. Chem. C, 2007, 111, 4990.

[6] Shockley, W.; Queisser, H.J. Detailed balance limit of efficiency of p-n junction solar cells. Appl. Phys. Lett., 1961, 32, 510.

[7] Tomar, M.S. Photovoltaic properties of $\mathrm{ZnO} / \mathrm{p}-\mathrm{CdTe}$ thin film heterojunctions. Thin Solid Films, 1988, 164, 295.

[8] Wary, G.; Kachary, T.; Rahman, A. Thermal and Doping Effect on $\mathrm{Sn} /(\mathrm{n}) \mathrm{ZnO}$ Schottky Junction and Its Performance as a PV Effect. Int. J. Thermophys., 2006, 27, 332.

[9] Gomez-Daza, O.; Campos, J.; Sanchez, A.; Banos, L.; Nair, M.T.S.; Nair, P.K. Mechanism of formation of highly photosensitive $\mathrm{CdSe} / \mathrm{ZnO}$ composite coatings obtained by sintering $\mathrm{CdSe} / \mathrm{ZnCl} 2$ screen printed layers. J. Electrochem. Soc., 2001, 148, G330.

[10] Izaki, M.; Mizuno, K.; Shinagaw, T.; Inaba, M.; Tasaka, A. Photochemical Construction of Photovoltaic Device Composed of pCopper(I) Oxide and n-Zinc Oxide. J. Electrochem. Soc., 2006, 153, C668.

[11] Minami, T.; Miyata, T.; Ihara, K.; Minamino, Y.; Tsukada, S. Effect of $\mathrm{ZnO}$ film deposition methods on the photovoltaic properties of $\mathrm{ZnO}-\mathrm{Cu} 2 \mathrm{O}$ heterojunction devices. Thin Solid Films, 2006, 494, 47.

[12] Fu, Z.X.; Lin, B.X.; Liao, G.H. Photovoltaic Effect of $\mathrm{ZnO} / \mathrm{Si}$ Heterostructure. Chin. Phys. Lett., 1999, 16, 753.

[13] Liu, C.H.; Chen, Y.L.; Lin, B.X.; Zhu, J.J.; Fu, Z.X.; Peng, C.; Yang, Z. Electrical Properties of the $\mathrm{ZnO} / \mathrm{Si}$ Heterostructure. Chin. Phys. Lett., 2001, 18, 1108.

[14] Beek, W.J.E.; Wienk, M.M.; Janssen, R.A. Efficient hybrid solar cells from $\mathrm{ZnO}$ nanoparticles and a conjugated polymer. $J$. Adv. Mater., 2004, 16, 1009.

[15] Beek, W.J.E.; Wienk, M.M.; Janssen, E.A.J. Hybrid Polymer Solar cells based on zinc oxide. J. Mater. Chem., 2005, 15, 2985.

[16] Beek, W.J.E.; Wienk, M.M.; Kemerink, M.; Yang, X.; Janssen, R.A.J. Hybrid zinc oxide conjugated polymer bulk heterojunction solar cells. J. Phys. Chem. B. 2005, 109, 9505.

[17] Beek, W. J. E.; Sloof, L. H.; Wienk, M. M.; Kroon, J. M.; Janssen, R. A. J. Hybrid solar cells using a zinc oxide precursor and a conjugated polymer. Adv. Funct. Mater., 2005, 15, 1703.

[18] Beek, W.J.E.; Wienk, M.M.; Janssen, R.A J. Hybrid solar cells from regioregular polythiophene and $\mathrm{ZnO}$ nanoparticles. Adv. Funct. Mater., 2006, 16, 1112.

[19] Peiró, A.M.; Ravirajan, P.; Govender, K.; Boyle, D.S.; O’Brien, P.; Bradley, D.D.C.; Nelson, J.; Durrant, J.R. Hybrid polymer/metal oxide solar cells based on $\mathrm{ZnO}$ columnar structures. J. Mater. Chem., 2006, 16, 2088.

[20] Olson, D.C.; Piris, J.; Collins, R.T.; Shaheen, S.E.; Ginley, D.S. Hybrid photovoltaic devices of polymer and $\mathrm{ZnO}$ nanofiber composites.Thin Solid Films, 2006, 496, 26.

[21] Lira-Cantu, M.; Krebs, F. C. Hybrid solar cells based on MEHPPV and thin film semiconductor oxides (TiO2, Nb2O5, $\mathrm{ZnO}$, $\mathrm{CeO} 2$ and $\mathrm{CeO} 2-\mathrm{TiO} 2)$ : Performance improvement during longtime irradiation. Solar. Energy Mater. Solar. Cells, 2006, 90, 2076.

[22] Keis, K.; Bauer, C.; Boschloo, G.; Hagfeldt, A.; Westermark, K.; Rensmo, H.; Siegbahn, H. Nanostructured $\mathrm{ZnO}$ electrodes for dyesensitized solar cell applications. J. Photochem. Photobiol. A, 2002, $148,57$.

[23] Basic Research Needs for Solar Energy Utilization; U.S. Department of Energy, U.S. Government Printing Office: Washington,
DC, Report based on a BES Workshop on Solar Energy Utilization, April 18-21, 2005.

[24] Dloczik, L.; Engelhardt, R.; Ernst, K.; Fiechter, S.; Sieber, I.; Konenkamp, R. Hexagonal nanotubes of $\mathrm{ZnS}$ by chemical conversion of monocrystalline $\mathrm{ZnO}$ columns. Appl. Phys. Lett., 2001, 78, 3687.

[25] Lokhande, C.; Pathan, H.M.; Giersig, M.; Tributsch, H. Preparation of $\mathrm{Zn}_{\mathrm{x}}(\mathrm{O}, \mathrm{S})_{\mathrm{y}}$ thin films using modified chemical bath deposition method. Appl. Surf. Sci,. 2002, 187, 101.

[26] Konenkamp, R.; Dloczik, L.; Ernst, K.; Olesch, C. Nano-structures for solar cells with extremely thin absorbers. Physica E, 2002, 14 , 219.

[27] Sankapal, B.R.; Sartale, S.D.; Lokhande, C.D.; Ennaoui, A Chemical synthesis of Cd-free wide band gap materials for solar cells. Solar. Energy Mater. Solar. Cells, 2004, 83, 447.

[28] Zhang, H.; Yang, D.; Ma, X.; Que, D. A versatile solution route for oxide/sulfide core-shell nanostructures and nonlayered sulfide nanotubes. Nanotechnology, 2005, 16, 2721.

[29] Yan, C.; Xue, D. Conversion of $\mathrm{ZnO}$ Nanorod Arrays into $\mathrm{ZnO} / \mathrm{ZnS}$ Nanocable and $\mathrm{ZnS}$ Nanotube Arrays via an in Situ Chemistry Strategy. J. Phys. Chem. B, 2006, 110, 25850.

[30] Panda, S.K.; Dev, A.; Chaudhuri, S. Fabrication and Luminescent Properties of c-Axis Oriented $\mathrm{ZnO}-\mathrm{ZnS}$ Core-Shell and $\mathrm{ZnS}$ Nanorod Arrays by Sulfidation of Aligned ZnO Nanorod Arrays. $J$. Phys. Chem. C, 2007, 111, 5039.

[31] Brabec, C.J.; Sariciftci, N.S.; Hummelen, J.C. Plastic Solar Cells. Adv. Funct. Mater., 2001, 11, 15.

[32] Coakley, K.M.; McGehee, M D. Conjugated Polymer Photovoltaic Cells. Chem. Mater., 2004, 16, 4533.

[33] Hoppe, H.; Sariciftci, N. S. Organic solar cells: An overview. J. Mater. Res., 2004, 19, 1924.

[34] Hansel, H.; Zettl, H.; Krausch, G.; Kissilev, R.; Thelakkat, M.; Schmidt, H.W. Optical and electronic contributions in doubleheterojuntion organic thin-film solar cells. Adv. Mater. Weinheim, Ger., 2003, 15, 2056.

[35] Kim, J.Y.; Kim, S.H.; Lee, H.H.; Lee, K.; Ma, W.; Gong, X.; Heeger, A J. New Architecture for High-Efficiency Polymer Photovoltaic Cells Using Solution-Based Titanium Oxide as an Optical Spacer. Adv. Mater. Weinheim, Ger., 2006, 18, 572.

[36] Gilot, J.; Barbu, I.; Wienk, M.M.; Janssena, R.A. The use of $\mathrm{ZnO}$ as optical spacer in polymer solar cells: Theoretical and experimental study. J. Appl. Phys. Lett., 2009, 91, 113520.

[37] Woll, C. The chemistry and physics of zinc oxide surfaces. Prog. Surf. Sci., 2007, 82, 55.

[38] Hosono, E.; Fujihara, S.; Kimura, T. Fabrication of nanocrystalline $\mathrm{ZnO}$ thick films for solar cells. Key Eng. Mater., 2002, 216, 69.

[39] Muller, J.; Schope, G.; Kluth, O.; Rech, B.; Sittinger, V.; Szyszka, B.; Geyer, R.; Lechner, P.; Schade, H.; Ruske, M.; Dittmar, G.; Bochem, H.P. State of the art mid-frequency sputtered $\mathrm{ZnO}$ films for thin film silicon solar cells and modules. Thin Solid Films, 2003, 442, 158.

[40] Gopel, W. Chemisorption and charge transfer at ionic semiconductor surfaces: Implications in designing gas sensors. Prog. Surf. Sci., $\mathbf{1 9 8 5}, 20,9$.

[41] Hishinuma, N. High-sensitivity $\mathrm{ZnO}$-semiconductor detector for atomic hydrogen beams. Rev. Sci. Instrum., 1981, 52, 313.

[42] Krummel C.; Freiling, A.; Schmidt, R.; Kelleter, J.; Wollnik, H.; Kohl, C.D. Fresenius. Induced zinc desorption from zinc oxide during exposure to a reducing agent. J. Anal. Chem., 1995, 353, 521.

[43] Latil S.; Roche, S.; Mayou, D.; Charlier, J.C. Mesoscopic Transport in Chemically Doped Carbon Nanotubes. Phys. Rev. Lett., 2004, 92, 256805-1.

[44] Rhee, J.H.; Ha, B.; Sharma, S.C. Electronic structure and electrical properties of Na-doped C60. Thin Solid Films, 2008, 517, 522.

[45] Gomez, H.; Maldonado, A.; Olvera, M. de la L.; Acosta, D.R. Gallium-doped $\mathrm{ZnO}$ thin films deposited by chemical spray. Solar. Energ. Mater. Solar. Cells, 2005, 87, 107.

[46] Seike, M.; Yanase, A.; Sato, K.; Katayama, H. Yoshida. Materials Design of 4d-Transition-Metal-Doped Transparent and HalfMetallic Ferromagnets with K2S-Based Diluted Magnetic Semiconductors. Jpn. J. Appl. Phys., 2003, 42, 1061.

[47] Murakami, M.; Yokohama, Y.; Matsumoto, T.; Hasegawa, P.; Ahmet, K.; Nakajima, T.; Chikyow, H.; Ofuchi, H.; Koinumab, Cobalt valence states and origins of ferromagnetism in Co doped $\mathrm{TiO}_{2}$ rutile thin films. J. Appl. Phys., 2004, 95, 5330. 
[48] Wang, Q.; Sun, Q.; Jena, P.; Hu, Z.; Note, R.; Kawazoe, Y. Firstprinciples study of magnetic properties in V-doped ZnO. Appl. Phys. Lett., 2007, 91, 063116.

[49] Jie, J.; Wang, G.; Han, X.; Yu, Q.; Liao, Y.; Li, G.; Hou, J.G. Indium-doped zinc oxide nanobelts. Chem. Phys. Lett., 2004, 387, 466.

[50] Pichierri, F. Substitution effects on the frontier orbitals of 3,4,9,10perylene bis(dicarboximide). A computational quantum chemistry study with insights into the electronic properties of organic semiconductors. J. Mol. Struct. (Theochem)., 2004, 686, 57.

[51] Pan, J.H.; Chiu, H.L.; Wang, B.Ch. Theoretical investigation of carbazole derivatives as hole-transporting materials in OLEDs. $J$. Mol. Struct. (Theochem)., 2005, 725, 89.

[52] Hwan, Y.; Park, H.; Rho, H.H.; Park, N.G.; Kim, Y.S. Theoretical investigation of tetra-substituted pyrenes for organic light emitting diodes. Curr. Appl. Phys., 2006, 6, 691.

[53] Glossman-Mitnik, D.; Barraza-Jiménez, D.; Flores-Hidalgo, A.; Rodríguez-Valdez, L.M. Molecular structure and substitution effects on diphenylanthrazolines for organic semiconductors: A theoretical study. J. Mol. Struct. (Theochem)., 2008, 863, 99.

[54] Barraza-Jimenez, D.; Flores-Hidalgo, A.; Glossman-Mitnik, D. Theoretical analysis of anthracene and its carbonyl and carboxyl derivatives using DFT and TD-DFT. J. Mol. Struct. (Theochem)., 2008, 894, 64 .

[55] Ginley D.S.; Bright, C. Transparent conducting oxides. MRS Bull., 2000, 25,15 .

[56] Shen, G.; Cho, J.H.; Yoo, J. K.; Yi, G.C.; Lee, Ch. J. Synthesis and Optical Properties of S-Doped ZnO Nanostructures: Nanonails and Nanowires. J. Phys. Chem. B, 2005, 109, 5491.

[57] Shen, G.; Cho, J.H.; Jung, S. I.; Lee, Ch. Synthesis and characterization of S-doped $\mathrm{ZnO}$ nanowires produced by a simple solutionconversion process. J. Chem. Phys. Lett., 2005, 401, 529.

[58] Perdew, J.P. Atoms, molecules, solids, and surfaces: Applications of the generalized gradient approxi-mation for exchange and correlation. Phys. Rev. B, 1992, 46, 6671.

[59] White, J.A.; Bird, D.M. Implementation of gradient-corrected exchange-correlation potentials in Car-Parrinello total-energy calculations. Phys. Rev. B, 1994, 50, 4954.

[60] Perdew, J.P.; Burke, K.; Ernzerhof, M. Generalized Gradient Approximation Made Simple. Phys. Rev. Lett., 1996, 77, 3865.
[61] Payne, M.C. Rev. Iterative minimization techniques for ab initio total-energy calculations: molecular dynamics and conjugate gradients. Mod. Phys., 1992, 64, 1050.

[62] Milman, V.; Winkler, B.; White, J.A.; Pickard, C.J.; Payne, M.C.; Akhmatskaya, E.V.; Nobes, R.H. Electronic structure, properties, and phase stability of inorganic crystals: A pseudopotential planewave study. Int. J. Quantum Chem., 2000, 77, 895.

[63] CASTEP is is a state-of-the-art quantum mechanics-based program by Accelrys Software inc., Materials Studio Release Notes, Release 4.4, San Diego: Accelrys Software Inc. 2008.

[64] Vanderbilt, D. Soft self-consistent pseudopotentials in a generalized eigenvalue formalism. Phys. Rev. B, 1990, 41, 7892.

[65] Laasonen, K.; Car, R.; Lee, C.; Vanderbilt, D. Implementation of ultrasoft pseudopotentials in ab initio molecular dynamics. Phys. Rev. B, 1991, 43, 6796.

[66] Ihm, J.; Zunger, A.; Cohen, M.L. Momentum-space formalism for the total energy of solids. J. Phys. C, 1979, 12, 4409.

[67] Kresse, G.; Furthmuller, Efficient iterative schemes for ab initio total-energy calculations using a plane-wave basis set. J. Phys. Rev. $B, 1996,54,11169$.

[68] Pfrommer, B.G.; Cote, M.; Louie, S.G.; Cohen, M.L. Relaxation of Crystals with the Quasi-Newton Method. J. Comput. Phys., 1997, $131,133$.

[69] Levine, Z.H.; Allan, D.C. Linear optical response in silicon and germanium including self-energy effects. Phys. Rev. Lett., 1989, 63, 1719 .

[70] Gonze, X.; Lee, C. First-principles responses of solids to atomic displacements and homogeneous electric fields: Implementation of a conjugate-gradient algorithm. Phys. Rev. B, 1997, 55, 10337.

[71] Özgür, Ü.; Alivov, Y.I.; Liu, C.; Teke, A.; Reshchikov, M.A.; Doğan, S.; Avrutin, V.; Cho, S.J.; Morkoç, H. A comprehensive review of $\mathrm{ZnO}$ materials and devices. J. Appl. Phys., 2005, 98, 041301.

[72] Kar, S.; Dutta, P.; Pal, T.; Ghosh, S. Simple solvothermal route to synthesize $\mathrm{S}$-doped $\mathrm{ZnO}$ nanonails and $\mathrm{ZnS} / \mathrm{ZnO}$ core/shell nanorods. Chem. Phys. Lett., 2009, 473, 102.

[73] Schrier, J.; Demchenko, D.O.; Wang, L.W. Optical Properties of $\mathrm{ZnO} / \mathrm{ZnS}$ and $\mathrm{ZnO} / \mathrm{ZnTe}$ Heterostructures for Photovoltaic Applications. Nano. Lett., 2007, 7, 2377.

(C) Flores-Hidalgo et al.; Licensee Bentham Open .

This is an open access article licensed under the terms of the Creative Commons Attribution Non-Commercial License (http://creativecommons.org/licenses/by-nc/3.0/) which permits unrestricted, non-commercial use, distribution and reproduction in any medium, provided the work is properly cited. 